\title{
Melanoma Incidence in Czech Republic, the Relation between Histology, Body Site of Melanoma, and Duration of Lesions
}

\author{
Jarmila Čelakovská1,*, Josef Bukač² Lenka Čáková1, Marie Šimková1, Eva Jandová ${ }^{1}$
}

\begin{abstract}
Aim: To evaluate the occurrence of melanoma in the period 1996-2017 in East Bohemia region in the Czech Republic. Method: We studied the incidence of melanoma and the age of diagnosis (adjusted calculation) and the parameters such as histology, body site of lesions, the length of the duration of lesions in 2810 patients. Results and conclusion: No change in the occurrence of melanoma and in age of melanoma during this period was found. The difference between men and women was not confirmed in histology, but the difference between men and women was confirmed in the body site of lesion and in the length of duration of lesion. No relation between the length of duration of lesions from which melanoma had originated and its histology was confirmed. The relation was confirmed between histology and body site of melanoma. The relation between the body site and the length of duration of previous lesions was confirmed also. The increasing occurrence of melanoma on the trunk according to the duration of the previous lesions was confirmed.

\section{KEYWORDS}

incidence of melanoma; histology of melanoma; body site of melanoma

\section{AUTHOR AFFILIATIONS}

${ }^{1}$ Department of Dermatology and Venereology Faculty Hospital and Medical Faculty of Charles University, Hradec Králové, Czech Republic

2 Department of Medical Biophysics, Medical Faculty of Charles University, Hradec Králové, Czech Republic

* Corresponding author: Department of Dermatology and Venereology, Faculty Hospital and Medical Faculty of Charles University, Hradec Králové, Czech Republic; e-mail: Celakovskaj@lfhk.cuni.cz
\end{abstract}




\section{KEY POINTS}

Question: What is the incidence of melanoma and is there any relation between the histology of melanoma, body site of melanoma, and the duration of lesion?

Findings: 2810 patients with a new diagnosis of melanoma were examined in the period of 1996-2017. The change in the occurrence of new melanoma and the age of melanoma was not confirmed. The relations between the followed parameters are shown in the study.

Meanings: The increase in the occurrence of melanoma on the trunk according to the duration of the previous lesions was confirmed; women suffer significantly more often from melanoma on lower limbs and on upper limbs, men suffer significantly more from melanoma on the trunk.

\section{INTRODUCTION}

Melanoma is one of the most malignant skin tumors with constantly rising incidence worldwide, especially in fairskinned populations (1-3). Historically, melanoma was a rare cancer, but in the last 50 years its incidence has risen faster than almost any other cancer. Skin cancer (the majority attributed to melanoma) was the cause of almost 2000 deaths in Australia in 2010 and it is currently the most common cancer in young Australians aged 15 to 39 years (4-7). In the United States alone, 87,110 individuals were predicted to be diagnosed with melanoma in $2017(2,5)$. If melanoma is diagnosed in its early stages, resection of the lesion is associated with favourable survival rates $(3,8)$. Once melanoma is advanced, surgery is no longer sufficient and the disease becomes more difficult to treat $(3,8-10)$. However, more recently developed immunotherapeutic treatments combined with radiation can improve survival further to several years (9).

As the incidence of melanoma steadily increases in both sexes, further improvement in primary prevention and early detection strategies is crucial (11). Melanoma arises through multiple various causal pathways and reflects a dynamic interdependence between environmental factors and genetic alterations. Epidemiological data support two major pathways in the pathogenesis of cutaneous melanoma: one by cumulative sun exposure to the site of the future melanoma in sun sensitive people and other by early sun exposure and nevus proneness, promoted by host factors, intermittent sun exposure, or both (12-18).

THE AIM OF THE STUDY IS TO EVALUATE:

1) The occurrence of new melanoma in years 1996-2017 in men and in women.

2) If there is some difference in the occurrence of new melanoma from the year 2002 to the year 2017 and if there is some difference in age of diagnosis (the incidence).

3) If there is a difference between men and women in parameters such as histology, body site of lesions, the length of the duration of lesions.

4) The relation between the histology and the body site of melanoma.
5) The relation between the length of the duration of lesion and the body site of melanoma.

6) The relation between the histology and the length of the duration of lesions from which the melanoma had arisen.

\section{PATIENTS AND METHODS}

This is an epidemiological study based on the examination of patients with a new histopathologically confirmed primary melanoma (lentigo maligna, melanoma in situ, invasive cutaneous superficial or nodular, mucosal melanoma or unknown primary melanoma) in the period 1996-2017. All these patients were examined at the Department of Dermatology, Faculty Hospital, Hradec Králové, Charles University, Czech Republic. The diagnosis of melanoma was made according to its histology. Patients' information and degree of spread of the melanoma was obtained during the examination of patients at out-patient department in the Department of Dermatology, Faculty Hospital Hradec, Králové, Charles University, Czech Republic. We evaluated these data: 1) The occurrence of new melanoma in years 1996-2017 in men and in women. 2) If there is some difference in the occurrences of new melanoma from the year 2002 to the year 2017 and if there is some difference in age of diagnosis (the incidence). 3) For how long the patient had observed the skin lesion from which the melanoma was confirmed - since childhood, 0-4 years, 5-9 years, more than 9 years. 4 ) The body site of lesion - face (including neck, scalp, ears), trunk, upper limbs (including hand, axillae), lower limbs (including feet plantar, subungual, heel, metatarsus and dorsum). 5) Histology of lesion - we distinguished nodular melanoma, superficial melanoma, melanoma in situ, lentigo maligna. Cases of the four main histological subtypes were evaluated in this study. The cases of mucosal, desmoplastic melanoma and melanoma of unknown origin are also included to the whole number of melanomas examined in this period.

This study was approved by Ethics commitee of Faculty Hospital Hradec Králové, Charles University, Czech Republic. There is no conflict of interest. Consolidated Standards of Reporting Trials and Strengthening the Reporting of Observational Studies in Epidemiology guidelines were followed.

\section{STATISTICAL ANALYSIS}

We evaluated 1) The occurrence of new melanoma in years 1996-2017 in men and in women 2) If there is some change in the occurrence of new melanoma (the incidence) from the year 2002 to the year 2017 and if there is some difference in age of diagnosis.

The age distribution changes year after year. This aging of the society is caused mainly by the post war baby boom repeated one generation later. This is the reason why we have to use standardization to be able to compare the number of patients in various years. We used the year 2017 as a standard. 
In each year we formed age groups five years wide, that is, 0-4, 5-9, 10-14, etc. In each year we counted the number of patients with a certain type of melanoma for each group and divided it by the number of inhabitants in that group in the given year. That gave us the age-specific incidence. When we multiplied it by the number of inhabitants in the age group in the standard year, we obtained what we called an adjusted number of patients in the age group for the given year. We added the adjusted numbers over all the age groups in the given year to obtain an adjusted number of patients in that year.

To calculate the average age of patients in a given year, we followed the idea that is used when we calculate the mean when only a histogram is presented. We took the midpoint of each group in a given year, multiplied it by the adjusted number of patients in the group and summed the products up over all the groups in the given year. When the sum of products obtained in this manner was divided by the adjusted number of patients in that year, it gave us the adjusted average age in that year.

Unfortunately, major administrative changes were made as to the division of the country into smaller regions during the year 2001. These changes made the distributions of ages incomparable and intractable. This was the reason

Tab. 1 Number of patients with new diagnosis of melanoma in the years 1996-2017.

\begin{tabular}{|c|c|c|c|c|c|c|}
\hline \multirow[b]{2}{*}{ Year } & \multicolumn{2}{|c|}{ No. of patients } & \multirow[b]{2}{*}{ Total } & \multicolumn{2}{|c|}{ No. of patients in $\%$} & \multirow[b]{2}{*}{ Total \% } \\
\hline & Men & Women & & Men & Women & \\
\hline 1996 & 48 & 48 & 96 & 50.0 & 50.0 & 100.0 \\
\hline 1997 & 45 & 50 & 95 & 47.4 & 52.6 & 100.0 \\
\hline 1998 & 37 & 42 & 79 & 46.8 & 53.2 & 100.0 \\
\hline 1999 & 48 & 63 & 111 & 43.2 & 56.8 & 100.0 \\
\hline 2000 & 48 & 57 & 105 & 45.7 & 54.3 & 100.0 \\
\hline 2001 & 41 & 53 & 94 & 43.6 & 56.4 & 100.0 \\
\hline 2002 & 54 & 67 & 121 & 44.6 & 55.4 & 100.0 \\
\hline 2003 & 49 & 58 & 107 & 45.8 & 54.2 & 100.0 \\
\hline 2004 & 71 & 73 & 144 & 49.3 & 50.7 & 100.0 \\
\hline 2005 & 72 & 67 & 139 & 51.8 & 48.2 & 100.0 \\
\hline 2006 & 53 & 64 & 117 & 45.3 & 54.7 & 100.0 \\
\hline 2007 & 68 & 62 & 130 & 52.3 & 47.7 & 100.0 \\
\hline 2008 & 71 & 71 & 142 & 50.0 & 50.0 & 100.0 \\
\hline 2009 & 85 & 69 & 154 & 55.2 & 44.8 & 100.0 \\
\hline 2010 & 56 & 57 & 113 & 49.6 & 50.4 & 100.0 \\
\hline 2011 & 59 & 74 & 133 & 44.4 & 55.6 & 100.0 \\
\hline 2012 & 82 & 88 & 170 & 48.2 & 51.8 & 100.0 \\
\hline 2013 & 63 & 73 & 136 & 46.3 & 53.7 & 100.0 \\
\hline 2014 & 79 & 73 & 152 & 52.0 & 48.0 & 100.0 \\
\hline 2015 & 76 & 69 & 145 & 52.4 & 47.6 & 100.0 \\
\hline 2016 & 82 & 94 & 176 & 46.6 & 53.4 & 100.0 \\
\hline 2017 & 82 & 69 & 151 & 54.3 & 45.7 & 100.0 \\
\hline total & 1369 & 1441 & 2810 & & & \\
\hline$p$-value & 0.887 & & & & & \\
\hline
\end{tabular}

The statistical difference between men and women was not confirmed $(p$-value $=0.887)$. why we could make adjustment to numbers of patients and calculations of adjusted ages only beginning with the year 2002. Since the year 2017 was the last one in which the patients' data were recorded, sixteen years of adjusted numbers and ages of patients were available. Regarding the evaluation of the relation between other parameters (histology of melanoma and body site of melanoma; histology of melanoma and the length of the duration of lesion; body site of melanoma and duration of lesions), we included the patients from the period 1996-2012. Pairs of these classifications were entered in the contingency tables and the chisquare test for independence of these classifications was perfomed with the level of significance set to $1 \%$.

\section{RESULTS}

\section{1) THE OCCURRENCE OF NEW MELANOMA \\ IN YEARS 1996-2017 IN MEN AND IN WOMEN.}

In the period 1996-2017, altogether 2810 patients with new a diagnosis of melanoma were examined, 1369 men (54.3\%) and 1441 women (45.7\%), 70 of them suffered from multiple melanoma. The cases of mucosal, desmoplastic melanoma, and melanoma of unknown origin are also included in the whole number of melanoma examined in this period. The number of patients with new a diagnosis of melanoma in every year of this period is shown in Table 1 . The difference in the occurrence of melanoma between men and women was not confirmed.

Supplement to Table 1. The statistical evaluation of the difference of the occurrence of new melanoma and the age of the diagnosis in period 2002-2017 (adjusted number of patients with melanoma and adjusted average age of diagnosis). The difference in the occurrence of melanoma in the period 2002-2017 was not confirmed. The statistical difference in age of melanoma diagnosis was not confirmed either.

\begin{tabular}{|l|c|c|}
\hline \multicolumn{3}{|l|}{$\begin{array}{l}\text { The calculation of the difference in the occurrence } \\
\text { of melanoma and the difference of age }\end{array}$} \\
\hline Year & $\begin{array}{l}\text { Adjusted number } \\
\text { of patients }\end{array}$ & $\begin{array}{l}\text { Average adjusted age } \\
\text { of diagnosis }\end{array}$ \\
\hline 2002 & 140.9 & 62.1 \\
\hline 2003 & 122.0 & 59.3 \\
\hline 2004 & 162.9 & 59.5 \\
\hline 2005 & 158.5 & 62.9 \\
\hline 2006 & 131.7 & 60.2 \\
\hline 2007 & 141.8 & 60.2 \\
\hline 2008 & 157.2 & 63.3 \\
\hline 2009 & 167.7 & 61.3 \\
\hline 2010 & 117.7 & 60.2 \\
\hline 2011 & 134.8 & 59.8 \\
\hline 2012 & 178.9 & 59.2 \\
\hline 2013 & 143.8 & 60.5 \\
\hline 2014 & 155.9 & 60.4 \\
\hline 2015 & 145.9 & 60.7 \\
\hline 2016 & 177.4 & 60.2 \\
\hline 2017 & 151.0 & 61.3 \\
\hline$p-v a l u e$ & 0.23 & 0.617 \\
\hline
\end{tabular}


2) IF THERE IS SOME DIFFERENCE IN THE OCCURRENCE OF NEW MELANOMA FROM THE YEAR 2002 TO THE YEAR 2017 AND IF THERE IS SOME DIFFERENCE IN AGE OF DIAGNOSIS (THE INCIDENCE).

We studied, if there is an increase in the occurrence of new melanomas and if there is some difference in age of melanoma diagnosis from the year 2002 to the year 2017. The calculations were done with respect to the number of inhabitants in the region and to average age of inhabitants in this region (the adjusted calculation). The statistical evaluation of the difference of the occurrence of new melanoma and the age of the diagnosis in period 2002-2017 was performed; it is shown in the Supplement to Table 1. The difference in the occurrence of melanoma in the period 2002-2017 was not confirmed. The statistical difference in age of melanoma diagnosis was not confirmed either.

\section{3) IF THERE IS A DIFFERENCE BETWEEN MEN}

AND WOMEN IN PARAMETERS SUCH AS HISTOLOGY, BODY SITE OF LESIONS, THE LENGTH

\section{OF THE DURATION OF LESIONS.}

Regarding the histology, lentigo maligna was confirmed in 217 patients (109 men - 8\% and 108 women $-7.5 \%$ ), melanoma in situ in 300 patients (140 men $-10.2 \%$ and 160 women $-11.1 \%$ ), melanoma nodulare in 423 patients (225 men - 16.4\% and 198 women - 13.7\%) and melanoma superficiale in 1870 patients ( 895 men $-65.4 \%$ and 975 women - 67.7\%). We have not confirmed the statistical difference in the occurrence of lentigo maligna, melanoma in situ, melanoma superficiale, or melanoma nodulare between men and women ( $p$-value $=0.200)$. Number of patients (men and women, including the number in\%) with lentigo maligna, melanoma in situ, melanoma superficiale, melanoma nodulare is shown in the Table 2 . The whole number of patients is 2810 . Regarding the body site -47 patients suffered from melanoma of unknown primary origin ( 24 men $-1.8 \%$ and 23 women $-1.6 \%$ ), 615 patients suffered from melanoma on lower limbs (157 men - 11.5\%

Tab. 2 Number of patients (men, women) with lentigo maligna, melanoma in situ, melanoma superficiale, melanoma nodulare. The whole number of patients is 2810 . The difference in the occurrence of lentigo maligna, melanoma in situ, melanoma superficiale and melanoma nodulare between men and women was not confirmed ( $p$-value $=0.200)$.

\begin{tabular}{|l|c|c|c|l|c|}
\hline \multicolumn{5}{|l|}{ Histology } \\
\hline & LM & M in situ & nod & sup & total patients \\
\hline men & 109 & 140 & 225 & 895 & 1369 \\
\hline women & 108 & 160 & 198 & 975 & 1441 \\
\hline total patients & 217 & 300 & 423 & 1870 & 2810 \\
\hline
\end{tabular}

\begin{tabular}{|l|l|c|l|l|r|}
\hline & LM & M in situ & nod & sup & total $\%$ \\
\hline men & $8.0 \%$ & $10.2 \%$ & $16.4 \%$ & $65.4 \%$ & $100.0 \%$ \\
\hline women & $7.5 \%$ & $11.1 \%$ & $13.7 \%$ & $67.7 \%$ & $100.0 \%$ \\
\hline p-value & 0.200 & \multicolumn{4}{|l}{} \\
\hline
\end{tabular}

Explanation: $L M$ - lentigo maligna, $M$ in situ - melanoma in situ, nod - melanoma nodulare, sup - melanoma superficiale and 458 women - $31.8 \%$ ), 522 patients on upper limbs (217 men $-15.9 \%$ and 305 women $-21.2 \%$ ), 355 patients on a face (167 men $-12.2 \%$ and 188 women - 13\%), 1250 patients on a trunk (794 men - 58\% and 456 women - 31.6\%), 21 patients suffered from mucosal melanoma (10 men - 0.7\% and 11 women $-0.8 \%)$. We have confirmed the difference between men and women regarding the body site ( $p$-val$u e=0.000$ ). Our study shows, that women suffer significantly more often from melanoma on lower limbs and on upper limbs, on the other hand, men suffer significantly more from melanoma on the trunk. Number of patients (men and women, including the number in \%) with different body site of melanoma (unknown origin, mucosal, upper limbs, lower limbs, face, trunk) is shown in Table 3. Regarding the duration of lesions, 2256 patients could

Tab. 3 Number of patients (men, women) with various body site of melanoma (unknown origin, mucosal, upper limbs, lower limbs, face, trunk). The whole number of patients is 2810 . The difference between men and women regarding the body site was confirmed ( $p$-value $=0.000)$.

\begin{tabular}{|l|c|c|c|c|c|r|c|}
\hline \multicolumn{7}{|l|}{ body site of melanoma } \\
\hline & unknown & lower & upper & mucosal & face & trunk & $\begin{array}{l}\text { total } \\
\text { patients }\end{array}$ \\
\hline men & 24 & 157 & 217 & 10 & 167 & 794 & 1369 \\
\hline women & 23 & 458 & 305 & 11 & 188 & 456 & 1441 \\
\hline $\begin{array}{l}\text { total } \\
\text { patients }\end{array}$ & 47 & 615 & 522 & 21 & 355 & 1250 & 2810 \\
\hline
\end{tabular}

\begin{tabular}{|l|c|l|l|l|l|l|l|}
\hline \multicolumn{7}{|c|}{ body site of melanoma } \\
\hline & unknown & lower & upper & mucosal & face & trunk & total \% \\
\hline men & $1.8 \%$ & $11.5 \%$ & $15.9 \%$ & $0.7 \%$ & $12.2 \%$ & $58.0 \%$ & $100.0 \%$ \\
\hline women & $1.6 \%$ & $31.8 \%$ & $21.2 \%$ & $0.8 \%$ & $13.0 \%$ & $31.6 \%$ & $100.0 \%$ \\
\hline p-value & 0.000 & & & & \\
\hline
\end{tabular}

Explanation: unknown - melanoma of unknown origin, lower lower limbs, upper - upper limbs

Tab. 4 Number of patients (men, women) with different duration of previous lesions, from which melanoma had originated (0-4 years, 5-9 years, over 9 year, from childhood). The whole number of patients is 2256. The difference between men and women regarding the duration of lesions was confirmed ( $p$-value $=0.002$ ). Patients, that could not determine the duration of lesion, are not included in this statistical evaluation.

\begin{tabular}{|l|r|c|c|c|c|}
\hline & \multicolumn{5}{|l|}{ duration of lesions } \\
\hline & $0-4$ y & $5-9 y$ & over 9y & childhood & $\begin{array}{l}\text { total } \\
\text { patients }\end{array}$ \\
\hline men & 486 & 100 & 193 & 267 & 1046 \\
\hline women & 660 & 103 & 178 & 269 & 1210 \\
\hline total patients & 1146 & 203 & 371 & 536 & 2256 \\
\hline
\end{tabular}

\begin{tabular}{|l|l|c|c|c|c|}
\hline \multicolumn{5}{|l|}{ duration of lesions } \\
\hline & $0-4 \mathrm{y}$ & $5-9 \mathrm{y}$ & over 9y & childhood & total \% \\
\hline men & $46.5 \%$ & $9.6 \%$ & $18.5 \%$ & $25.5 \%$ & $100.0 \%$ \\
\hline women & $54.5 \%$ & $8.5 \%$ & $14.7 \%$ & $22.2 \%$ & $100.0 \%$ \\
\hline p-value & 0.002 & \multicolumn{4}{|l|}{} \\
\hline
\end{tabular}


determine the duration of lesions: 1146 patients had observed the lesion in the duration of 0-4 years (486 men $46.5 \%$ and 660 women $-54.5 \%), 203$ patients had observed the lesions for 5-9 years (100 men - 9.6\% and 103 women $-8.5 \%), 371$ patients had observed the lesion for more than 9 years (193 men $-18.5 \%$ and 178 women - 14.7\%), 536 patients had observed the pigmenal nevus since childhood ( 267 men $-25.2 \%$ and 269 women $-22.2 \%$ ), 554 patients (25\%) could not state for how long they had observed the previous lesions from which melanoma had originated. These patients are not included in this statistical evaluation. We confirmed the statistical difference between men and women regarding the duration of lesions ( $p$-value = 0.002). Women suffer significantly more from melanoma in the duration of 0-4 years; the study shows, that the duration of lesion of 0-4 years was confirmed in $54.5 \%$ of women, but only in $46.5 \%$ of men (Table 4 ).

\section{4) THE RELATION BETWEEN HISTOLOGY AND BODY SITE OF MELANOMA.}

We evaluated the relation between the histology (lentigo maligna, melanoma in situ, nodular melanoma, superficial melanoma) and the body site of melanoma (lower limbs, upper limbs, face, trunk). The occurrence of lentigo maligna was recorded in $9.6 \%$ on lower limbs, in $13.5 \%$ on upper limbs, in $29.3 \%$ on a face and in $47.6 \%$ on a trunk. Melanoma in situ was recorded in $20.4 \%$ on lower limbs, in $25.2 \%$ on upper limbs, in $7.2 \%$ on a face, and in $47.2 \%$ on a trunk. Melanoma nodulare was recorded in $19.5 \%$ patients on lower limbs, in $21.6 \%$ on upper limbs, in $12.7 \%$ on a face, and in $46.2 \%$ on a trunk. Melanoma superficiale was recorded in $25 \%$ on lower limbs, in $18.1 \%$ on upper limbs, in $11.7 \%$ on a face, and in $45.2 \%$ on a trunk. The depend-

Tab. 5 The relation between the histology and the body site of melanoma (lower limbs, upper limbs, face, trunk). The relation was confirmed, $(p$-value $=0.000)$. Total number of patients is 2826 .

\begin{tabular}{|l|r|r|r|r|c|}
\hline \multicolumn{5}{|l|}{ body site } \\
\hline histology & $\begin{array}{l}\text { lower } \\
\text { limbs }\end{array}$ & $\begin{array}{l}\text { upper } \\
\text { limbs }\end{array}$ & face & trunk & $\begin{array}{l}\text { total } \\
\text { patients }\end{array}$ \\
\hline LM & 22 & 31 & 67 & 109 & 229 \\
\hline M in situ & 65 & 80 & 23 & 150 & 318 \\
\hline nod & 83 & 92 & 54 & 197 & 426 \\
\hline sup & 463 & 335 & 217 & 838 & 1853 \\
\hline total patients & 633 & 538 & 361 & 1294 & 2826 \\
\hline
\end{tabular}

\begin{tabular}{|l|c|l|l|l|l|}
\hline \multicolumn{5}{|l|}{ body site } \\
\hline histology & $\begin{array}{l}\text { lower } \\
\text { limbs }\end{array}$ & $\begin{array}{l}\text { upper } \\
\text { limbs }\end{array}$ & face & trunk & total $\%$ \\
\hline LM & $9.6 \%$ & $13.5 \%$ & $29.3 \%$ & $47.6 \%$ & $100.0 \%$ \\
\hline M in situ & $20.4 \%$ & $25.2 \%$ & $7.2 \%$ & $47.2 \%$ & $100.0 \%$ \\
\hline nod & $19.5 \%$ & $21.6 \%$ & $12.7 \%$ & $46.2 \%$ & $100.0 \%$ \\
\hline sup & $25.0 \%$ & $18.1 \%$ & $11.7 \%$ & $45.2 \%$ & $100.0 \%$ \\
\hline p-value & $0.000^{*}$ & & & \\
\hline
\end{tabular}

Explanation: LM - lentigo maligna, $M$ in situ - melanoma in situ, nod - melanoma nodulare, sup - melanoma superficiale ence between the histology and body site of lesions was confirmed, $p$-value $=0.000$. The total number of patients was 2826 . This relation is shown in Table 5. Our study shows, that lentigo maligna, melanoma in situ, melanoma nodulare and melanoma superficiale are found from $45.2 \%$ to $47.6 \%$ on a trunk, lentigo maligna is found on a face in $29.3 \%$, and in $9.6 \%$ of patients on lower limbs.

\section{5) THE RELATION BETWEEN THE LENGTH OF THE DURATION OF LESION AND THE BODY SITE OF MELANOMA.}

We evaluated the relation between the duration of lesions (0-4 years, 5-9 years, over 9 years, from childhood) and the body site of melanoma (lower limbs, upper limbs, face, trunk). The occurrence of melanoma in a duration of $0-4$ years was recorded in $27.4 \%$ on lower limbs, in $22.3 \%$ on upper limbs, in $16.7 \%$ on a face, and in $33.6 \%$ on a trunk. The occurrence of melanoma in the duration of 5-9 years was recorded in $16.9 \%$ on lower limbs, in $20.9 \%$ on upper limbs, in $20.9 \%$ on a face, and in $41.3 \%$ on a trunk. The occurrence of melanoma in the duration over 9 years was recorded in $22 \%$ patients on lower limbs, in $16.9 \%$ on upper limbs, in $16.6 \%$ on a face, and in $44.5 \%$ on a trunk. The occurrence of melanoma in a duration since childhood was recorded in $25.1 \%$ on lower limbs, in $18.6 \%$ on upper limbs, in $5.6 \%$ on face, and in $50.7 \%$ on trunk. The relation between the duration of lesions and body site of lesions was confirmed, $p$-value $=0.000$. The total number of patients was 2232. The relation is shown in Table 6. Our study shows that melanoma on the trunk was confirmed by the lesions since childhood in $50.7 \%$ but on the face from the lesions since childhood only in $5.6 \%$. We can observe the increase in the occurrence of melanoma on the trunk according to the duration of the previous lesions -

Tab. 6 The relation between the duration of lesions ( $0-4$ years, 5-9 years, over 9 years, from childhood) and the body site of melanoma (lower limbs, upper limbs, face, trunk). The relation was confirmed ( $p$-value $=0.000)$. Total number of patients is 2232 .

\begin{tabular}{|l|r|r|r|r|r|}
\hline \multicolumn{5}{|l|}{ body site } \\
\hline $\begin{array}{l}\text { duration } \\
\text { of lesion }\end{array}$ & $\begin{array}{l}\text { lower } \\
\text { limbs }\end{array}$ & $\begin{array}{l}\text { upper } \\
\text { limbs }\end{array}$ & face & trunk & $\begin{array}{l}\text { total } \\
\text { patients }\end{array}$ \\
\hline $0-4$ y & 307 & 250 & 187 & 377 & 1121 \\
\hline $5-9$ y & 34 & 42 & 42 & 83 & 201 \\
\hline over 9y & 82 & 63 & 62 & 166 & 373 \\
\hline childhood & 135 & 100 & 30 & 272 & 537 \\
\hline total patients & 558 & 455 & 321 & 898 & 2232 \\
\hline
\end{tabular}

\begin{tabular}{|l|l|l|l|l|l|}
\hline \multicolumn{5}{|l|}{ body site } \\
\hline $\begin{array}{l}\text { duration } \\
\text { of lesion }\end{array}$ & $\begin{array}{l}\text { lower } \\
\text { limbs }\end{array}$ & $\begin{array}{l}\text { upper } \\
\text { limbs }\end{array}$ & face & trunk & total \% \\
\hline $0-4 \mathrm{y}$ & $27.4 \%$ & $22.3 \%$ & $16.7 \%$ & $33.6 \%$ & $100.0 \%$ \\
\hline $5-9 \mathrm{y}$ & $16.9 \%$ & $20.9 \%$ & $20.9 \%$ & $41.3 \%$ & $100.0 \%$ \\
\hline over 9y & $22.0 \%$ & $16.9 \%$ & $16.6 \%$ & $44.5 \%$ & $100.0 \%$ \\
\hline childhood & $25.1 \%$ & $18.6 \%$ & $5.6 \%$ & $\mathbf{5 0 . 7} \%$ & $100.0 \%$ \\
\hline p-value & $0.000^{*}$ & & & \\
\hline
\end{tabular}


lesions in the duration of 0-4 years appear on the trunk in $33.6 \%$, in the duration of 5-9 years in $41.3 \%$, in the duration over 9 years in $44.5 \%$, and since childhood in $50.7 \%$.

\section{6) THE RELATION BETWEEN THE HISTOLOGY AND THE LENGTH OF THE DURATION OF LESION FROM WHICH THE MELANOMA HAD ARISEN.}

We evaluated the relation between the duration of lesions (0-4 years, 5-9 years, 10-19 years, over 19 years, since childhood) and the histology (lentigo maligna, melanoma in situ, nodular melanoma, superficial melanoma). From lesions in the duration of 0-4 years, lentigo maligna was confirmed in $7.8 \%$, melanoma in situ in $9.8 \%$, melanoma nodulare in $17 \%$, and melanoma superficiale in $65.4 \%$. From lesions in the duration of 5-9 years, lentigo maligna was confirmed in $8.3 \%$, melanoma in situ in $11.7 \%$, melanoma nodulare in $11.2 \%$ and melanoma superficiale in $68.8 \%$. From lesions in the duration of 10-19 years, lentigo maligna was confirmed in $7.4 \%$, melanoma in situ in $13.2 \%$, melanoma nodulare in $11.9 \%$, and melanoma superficiale in $67.5 \%$. From lesions in the duration over 19 years, lentigo maligna was confirmed in $11.1 \%$, melanoma in situ in $9.5 \%$, melanoma nodulare in $15.9 \%$, and melanoma superficiale in $63.5 \%$. From pigmented nevus since childhood, lentigo maligna was confirmed in $8.1 \%$, melanoma in situ in $8.9 \%$, melanoma nodulare in $15.2 \%$, and melanoma superficiale in $67.8 \%$. The relation between the duration of lesions and histology was not confirmed ( $p$-value $=0.390$ ). The total number of patients was 2271. The relation is shown in Table 7 .

Tab. 7 The relation between the duration of lesions ( $0-4$ years, 5-9 years, 10-19 years, over 19 years, from childhood) and the histology. The relation was not confirmed ( $p$-value $=0.390)$. Total number of patients is 2271 .

\begin{tabular}{|l|r|r|r|r|r|}
\hline \multicolumn{5}{|l|}{ histology } \\
\hline $\begin{array}{l}\text { duration } \\
\text { of lesions }\end{array}$ & \multicolumn{1}{l|}{ LM } & M in situ & nod & sup & $\begin{array}{l}\text { total } \\
\text { patients }\end{array}$ \\
\hline 0-4 y & 90 & 113 & 196 & 753 & 1152 \\
\hline $5-9$ y & 17 & 24 & 23 & 141 & 205 \\
\hline $10-19$ y & 23 & 41 & 37 & 210 & 311 \\
\hline over 19y & 7 & 6 & 10 & 40 & 63 \\
\hline childhood & 44 & 48 & 82 & 366 & 540 \\
\hline $\begin{array}{l}\text { total } \\
\text { patients }\end{array}$ & 181 & 232 & 348 & 1510 & 2271 \\
\hline
\end{tabular}

\begin{tabular}{|l|c|c|c|c|l|}
\hline \multicolumn{5}{|l|}{ histology } \\
\hline $\begin{array}{l}\text { duration } \\
\text { of lesions }\end{array}$ & LM & M in situ & nod & sup & total $\%$ \\
\hline $0-4$ y & $7.8 \%$ & $9.8 \%$ & $17.0 \%$ & $65.4 \%$ & $100.0 \%$ \\
\hline $5-9$ y & $8.3 \%$ & $11.7 \%$ & $11.2 \%$ & $68.8 \%$ & $100.0 \%$ \\
\hline $10-19 y$ & $7.4 \%$ & $13.2 \%$ & $11.9 \%$ & $67.5 \%$ & $100.0 \%$ \\
\hline over 19y & $11.1 \%$ & $9.5 \%$ & $15.9 \%$ & $63.5 \%$ & $100.0 \%$ \\
\hline childhood & $8.1 \%$ & $8.9 \%$ & $15.2 \%$ & $67.8 \%$ & $100.0 \%$ \\
\hline p-value & 0.390 & & & & \\
\hline
\end{tabular}

Explanation: LM - lentigo maligna, $M$ in situ - melanoma in situ, nod - melanoma nodulare, sup - melanoma superficiale

\section{DISCUSSION}

There have been many interesting papers regarding the epidemiology and incidence of melanoma to come out in recent years. According to the literature, further work is needed to understand fully the issues raised by several studies (20). In this study, we evaluated as the incidence both several parameters in epidemiology of melanoma in the period from the year 1996 to the year 2017 in East Bohemia region in the Czech Republic in middle Europe. There are 551 thousands inhabitants and the area of this region is 4,759 square $\mathrm{km}$.

The advantage of our study is that all patients included in this study were personaly examined and were followed at the Department of Dermatology, Faculty Hospital Hradec Králové, Charles University, Czech Republic. According to the adjusted calculation, we did not confirm the statistical important difference in the occurrence of new melanomas in the period from 2002 to 2017, neither between men and women; nor did we confirm the difference in age of melanoma diagnosis - the age of melanoma diagnosis is 59-62 years in this period. Also, we did not confirmed the difference in the occurrence of lentigo maligna, melanoma in situ, melanoma superficiale, and melanoma nodulare between men and women. On the other hand, we confirmed the statistical difference between men and women in the body site of melanoma and the length of the duration of lesions. Our study shows that women suffer significantly more often from melanoma on lower limbs (31.8\% women, $11.5 \%$ men) and on upper limbs ( $21.2 \%$ women, $15.9 \%$ men). On the other hand, men suffer significantly more from melanoma on the trunk (58\% of men versus $31.6 \%$ of women). The duration of lesion of $0-4$ years was confirmed in $54.5 \%$ of women but only in $46.5 \%$ of men.

We also evaluated the relation between the parameters, such as the histology, the length of the duration of lesion from which the melanoma had arisen, and the body site of melanoma. We confirmed that there is a significant relation of body site of melanoma to its histology and to the length of the duration of lesions which melanoma had arisen from. No relation was confirmed between the length of the duration of lesions and its histology. Our study shows that lentigo maligna, melanoma in situ, melanoma nodulare, and melanoma superficiale are found from $45.2 \%$ to $47.6 \%$ on a trunk but lentigo maligna is found more often on a face $(29.3 \%)$ and less often on lower limbs (9.6\%), melanoma in situ only in $7.2 \%$ on a face but in $20.4 \%$ on lower limbs. Melanoma from pigmented nevus from childhood was confirmed on the trunk in 50.7\%, but only in $5.6 \%$ on the face. We can observe the increasing occurrence of melanoma on a trunk according to the duration of the previous lesions - melanoma had arisen on the trunk from lesions in the duration of $0-4$ years in $33.6 \%$, in the duration of 5-9 years in $41.3 \%$, in the duration over 9 years in $44.5 \%$, and since childhood in $50.7 \%$ as mentioned above. Regarding the duration of lesions since childhood, we confirmed that 540 patients $(19 \%, 2810$ patients = $100 \%$ ) suffered from nevus pigmentosus from childhood.

Some of our results are in contrast to other studies. There is a universal agreement that the incidence of mel- 
anoma diagnoses is increasing and a similar trend has been observed in Europe $(21,22)$. Multiple studies using the US Surveillance, Epidemiology and End Results (SEER) Program and National Program of Cancer Registries have consistently reported increasing melanoma incidence between 1973 and 1997 (23-25) More recent studies (19922006 ) reported that melanoma incidence increased $3 \%$ to $4 \%$ per year across most demographic groups $(1,26)$. However, a recent study of the Centers for Disease Control and Prevention database suggests that incidence in New England states may be decreasing (27).

Finally, it has been suggested that the observed increased melanoma incidence may be an artifact of underreporting in earlier decades (28). Most of the studies cited above relied on SEER and National Program of Cancer Registries data to compare melanoma rates at different time points (29). Many previous epidemiologic studies were missing data on tumor thickness, and many registries did not capture in situ lesions $(30,31)$. These factors could account for an underrepresentation of thicker melanomas and overestimation of mortality from thin melanomas.

According to some studies, males are approximately 1.5-times more likely to develop a melanoma than females but the different prevalence in both sexes must be analyzed in relation to age: the incidence rate of melanoma is greater in women than in men until they reach the age of 40 years, however, by 75 years of age, the incidence is almost 3 -times as high in men than in women (32-34). According to other studies, higher melanoma rates have been mostly observed in elderly or male populations, whereas the female sex seems to represent an independent risk factor for early onset melanoma for women younger than 45 years (35-37). According to recent data, the rising melanoma trends mostly affect the older age groups, whereas the incidence seems to stabilize in the youngest age groups (24-44 years) (38). However, melanoma still affects mostly younger patients, with a median age diagnosis of 57-64 worldwide (38). This is in agreement with our study, the average age of new melanoma is 59-62 years according to our results.

Regarding the body site of melanoma, our study shows, that women suffer significantly more often from melanoma on lower limbs and on upper limbs, men suffer significantly more from melanoma on the trunk. According to some studies, the anatomical location of melanoma also varies according to gender. Males tend to have worse clinical and histological characteristics at primary diagnosis; melanomas in men are more often located on the head, neck, and trunk, commonly ulcerated and have a higher Breslow thickness $(39,40)$. Males are more likely to report greater exposure to the sun, mainly due to greater participation in outdoor work and leisure activities, compared to females (41). Females are likely to be more knowledgeable about skin cancer than males (42). However, the higher knowledge and use of sun protective measures among women conflicts with findings that women have a greater desire for a tan and their increased perception that a tan is healthy compared with men $(31,43)$. Two pathways have been hypothesized for the development of cutaneous melanoma: one typically affects the head and neck, a site with chronic sun damage, and the other affects the trunk, which is less exposed to the sun. These results appear to support the hypothesis of divergent pathways to melanoma and that recreational sun exposure and indoor tanning are associated with melanoma on the lower limbs, the most common site of melanoma in women. These findings appear to have important preventive implications $(44,45)$. This is in agreement with our results, that women suffer significantly more often from melanoma on lower limbs ( $31.8 \%$ of women versus $11.5 \%$ of men), men suffer significantly more often from melanoma on the trunk (58\% of men versus $31.6 \%$ of women).

In our study we confirmed that melanoma had originated from nevus pigmentosus from childhood in 540 patients $(19 \%)$ - on the trunk in $50.7 \%$ of patients, in $5.6 \%$ of patients on the face. According to the literature, approximately $25-33 \%$ of cutaneous melanomas derive from a benign, melanocytic nevus, whereas this percentage may be as high as $50 \%$ in patients with numerous nevi (17, 46-48). Transformation of nevi to melanoma occurs most commonly in non-chronically sun-damaged skin. Nevus-prone patients with an increased number of melanocytic nevi tend to develop melanomas at a younger age and on axial locations. On the other hand, nevus resistant patients with fewer nevi tend to develop de novo melanomas on habitually sun-exposed skin or at older ages (49, 50). There is a strong evidence that an intermittent pattern of sun exposure increases the melanoma risk. Chronic sun exposure shows no association or a weak inverse association with melanoma risk - it can explain the rare occurrence of melanoma from pigmented nevus from childhood on the face observed in our study. Episodic, intermittent, high-intensity exposure to sunlight has been linked to the development of melanoma in Australia $(5,6)$. Total lifetime sun exposure is positively associated with melanoma risk, but the relationship is weaker than that for intermittent sun exposure $(32,33,51,52)$. Sunburn is a marker of an intermittent pattern of sun exposure and there is a tendency for greater consistency of positive associations for sunburn than for intermittent exposure (32-35, 51, 52). Furthermore it may explain our results, as we suppose, that melanoma resulting from the nevus pigmentosus from childhood could be sunburned on the trunk, but there is chronic sun exposure on the face. Melanoma risk differs not only by a pattern of sun exposure but also by body site, age, and phenotype of a patient (36, 49). According to some studies, head and neck melanomas have been linked to chronic sun exposure with older age of diagnosis and melanoma on the trunk and limbs to younger ages and intermittent exposure. According to another study, sun exposure can cause melanoma on all body sites, but risks tend to be higher for usually sun-exposed sites than occasionally exposed sites (37, 53). For sunburn, strong positive associations have been found at all body sites (head/neck, trunk, arms, and legs) and with no significant site-specific differences in a recent meta-analyses and pooled analyses $(37,38,54)$. In our study, we confirmed a significant relation between the histology and body site of melanoma. Our study shows that lentigo maligna, melanoma in situ, melanoma nodulare, and melanoma superficiale are found to be from $45.2 \%$ to $47.6 \%$ on the trunk, but lentigo maligna is found more often on 
a face $(29.3 \%)$ and less often on lower limbs (9.6\%), melanoma in situ only in $7.2 \%$ on a face, but in $20.4 \%$ on lower limbs. Melanoma nodulare was confirmed only in $12.7 \%$ of patients on the face, but in $19.5 \%$ and $21.6 \%$ of patients on upper and lower limbs respectively and in $46.2 \%$ of patients on the trunk. According to the literature, in contrast to cutaneous superficial spreading melanoma, the occurrence of nodular melanoma and mucosal melanoma seems to be independent of UV exposure. Specifically, in the case of nodular melanoma, the influence of UV is controversially discussed in the literature. Some studies reported a higher prevalence of nodular melanoma on sun-exposed skin such as the lower limbs, head, and neck. However, nodular melanoma can also affect non-chronically sun-exposed body areas such as the trunk in fairbut also dark-skinned patients $(48,55-57)$.

Individuals with large or giant congenital melanocytic nevi (CMNs) at birth are at higher risk of melanoma development which increases according to the size of CMN and is the highest in those nevi traditionally designated as garment nevi (58-60). Also, personal history of a prior melanoma is a strong predictor for the development of a subsequent melanoma, with approximately tenfold increased risk (61). Additionally, melanoma seems to appear more commonly in immunosuppressed patients, including patients with prior organ transplantation, hematologic malignancies, or human immunodeficiency virus infection, as well as patients taking immunosuppressive medication (62).

The epidemiologic, genomic, and anatomic profiles of melanoma significantly differ across the world and mostly depend on a constellation of environmental and (epi) genetic factors (11). The purpose of our study was to contribute to the evaluation of the incidence of melanoma in East Bohemia region in the Czech Republic in middle Europe and to evaluate the relation between the followed parameters.

\section{CONCLUSION}

No statistical difference in the occurrence of new melanomas during the period 2002-2017 was found, furthermore, no difference in the age of patients with melanoma; also there is no difference in the occurrence between men and women. The difference between men and women was not confirmed in histology, but the difference between men and women was confirmed in the body site of lesion and in the length of duration of lesion. Women suffer significantly more often from melanoma on lower limbs and on upper limbs, men suffer significantly more from melanoma on the trunk. The length of the duration of lesion of 0-4 years to the diagnosis of melanoma was confirmed in $54.5 \%$ of women, but only in $46.5 \%$ of men. No relation between the length of duration of lesions from which melanoma had originated and its histology was confirmed. The relation was confirmed between histology and body site of melanoma. The increasing occurrence of melanoma on the trunk according to the duration of the previous lesions was confirmed.

\section{ACKNOWLEDGEMENTS}

I would like to thank the specialists from the regional pathology departments for the evaluation of the histology in patients suffering from melanoma.

\section{REFERENCES}

1. Linos E, Swetter SM, Cockburn MG, Colditz GA, Clarke CA. Increasing burden of melanoma in the United States. J Investig Dermatol 2009; 129(7): 1666-74.

2. Surveillance, Epidemiology, and End Results (SEER). Program Cancer Statistics Review, 1975-2013, National Cancer Institute [Internet] Nov, 2015. SEER data submission [cited posted to the SEER web site, 2016 Apr]. Available from: http://seer.cancer.gov/csr/1975_2013/.

3. Erdei E, Torres SM. A new understanding in the epidemiology of melanoma. Exp Rev Anticancer Ther 2010; 10(11): 1811-23.

4. Australian Bureau of Statistics. (2012). 3303.0. - Causes of death, Australia 2010: Underlying causes of death. (Excel spreadsheet). Canberra, Australia: ABS. Retrieved from www.abs.gov.au/AUSSTATS /abs@.nsf/DetailsPage/3303.02010.

5. GLOBOCAN 2012 v1.0, Cancer Incidence and Mortality Worldwide: IARC CancerBase No. 11 [Internet] 2013. Available from: http://globocan.iarc.fr.

6. Cancer Council ACT. (2017). Skin cancer in Australia. Available from: www.actcancer.org/prevention/sunsmart/skin-cancer-in-Australia.

7. Guy GP Jr, Thomas CC, Thompson T, Watson M, Massetti GM, Richardson LC. Vital signs: Melanoma incidence and mortality trends and projections - United States, 1982-2030. MMWR Morb Mortal Wkly Rep 2015; 64(21): 591-6.

8. Califano J, Nance M. Malignant melanoma. Facial Plast Surg Clin North Am 2009; 17(3): 337-48.

9. Filippi AR, Fava P, Badellino S, Astrua C, Ricardi U, Quaglino P. Radiotherapy and immune checkpoints inhibitors for advanced melanoma. Radiother Oncol 2016; 120(1): 1-12.

10. Goodson AG, Grossman D. Strategies for early melanoma detection: Approaches to the patient with nevi. J Am Acad Dermatol 2009; 60(5): 719-35. quiz 36-8.

11. Siegel RL, Miller KD, Jemal A. Cancer statistics, 2017. CA Cancer J Clin 2017; 67(1): 7-30.

12. Koh HK, Geller AC, Miller DR, Grossbart TA, Lew, RA. Prevention and early detection strategies for melanoma and skin cancer. Current status Arch Dermatol 1996; 132(4): 436-43.

13. Armstrong BK, Cust AE. Sun exposure and skin cancer, and the puzzle of cutaneous melanoma: a perspective on Fears et al. mathematical models of age and ultraviolet effects on the incidence of skin cancer among whites in the United States. Cancer Epidemiol 2017; 48: 147-56.

14. D'Orazio J, Jarrett S, Amaro-Ortiz A, Scott T. UV radiation and the skin. Int J Mol Sci 2013; 14(6): 12222-48.

15. Colantonio S, Bracken MB, Beecker, J. The association of indoor tanning and melanoma in adults: systematic review and meta-analysis. J Am Acad Dermatol 2014; 70(5): 847-57. e1-18.

16. Pawlak MT, Bui M, Amir M, Burkhardt DL, Chen AK, Dellavalle RP. Legislation restricting access to indoor tanning throughout the world. Arch Dermatol 2012; 148(9): 1006-12.

17. Bevona C, Goggins W, Quinn T, Fullerton J, Tsao H. Cutaneous melanomas associated with nevi. Arch Dermatol 2003; 139(12): 1620-4.

18. Haenssle HA, Mograby N, Ngassa, A, et al. Association of patient risk factors and frequency of nevus-associated cutaneous melanomas. JAMA Dermatol 2016; 152(3): 291-8.

19. Moher D, Hopewell S, Schulz KF, et al. For the CONSORT Group. CONSORT 2010 Explanation and Elaboration: Updated guidelines for reporting parallel group randomised trial. BMJ 2010; 340: 869.

20. Berg SA, Ming ME. Recent Advances in Our Understanding of the Epidemiology of Melanoma. Curr Derm Rep 2017; 6(3): 211-21.

21. Giblin AV, Thomas JM. Incidence, mortality and survival in cutaneous melanoma. J Plast Reconstr Aesthet Surg 2007; 60: 32-40.

22. Garbe C, Leiter U. Melanoma epidemiology and trends Clin Dermatol 2009; 27: 3-9.

23. Welch HG, Woloshin S, Schwartz LM. Skin biopsy rates and incidence of melanoma: population based ecological study. BMJ 2005; 331: 481.

24. Dennis LK. Analysis of the melanoma epidemic, both apparent and real: data from the 1973 through 1994 surveillance, epidemiology, and end results program registry. Arch Dermatol 1999; 135: 275-80.

25. Hall HI, Jamison P, Fulton JP, Clutter G, Roffers S, Parrish P. Reporting cutaneous melanoma to cancer registries in the United States. J Am Acad Dermatol 2003; 49: 624-30. 
26. Jemal A, Saraiya M, Patel P, et al. Recent trends in cutaneous melanoma incidence and death rates in the United States, 1992-2006. J Am Acad Dermatol 2011; 65(5 suppl 1): S17-S25, e1-3.

27. Mounessa, JS, Caravaglio JV, Dellavalle RP. Comparison of regional and state differences in melanoma rates in the United States: 2003 vs 2013. JAMA Dermatol 2017; 153: 345-7.

28. Cockburn M, Swetter SM, Peng D, Keegan TH, Deapen D, Clarke CA. Melanoma underreporting: why does it happen, how big is the problem, and how do we fix it? J Am Acad Dermatol 2008; 59: 1081-5.

29. Watson M, Johnson CJ, Chen VW, et al. Melanoma surveillance in the United States: overview of methods. J Am Acad Dermatol 2011; 65(5 suppl 1): S6-S16.

30. Shaikh WR, Weinstock MA, Halpern AC, Oliveria SA, Geller AC, Dusza SW. The characterization and potential impact of melanoma cases with unknown thickness in the United States' Surveillance, Epidemiology, and End Results Program, 1989-2008. Cancer Epidemiol 2013; 37: 64-70.

31. Gimotty PA, Shore R, Lozon NL, et al. Miscoding of melanoma thickness in SEER: research and clinical implications. J Invest Dermatol 2016; 136: 2168-72.

32. Rastrelli M, Tropea S, Rossi C, Alaibac M. Melanoma, Epidemiology, Risk Factors, Pathogenesis, Diagnosis and Classification. In vivo 2014; 28(6): 1005-11.

33. Johnson-Obaseki S, Labajian V, Corsten MJ, McDonald, J. Incidence of cutaneous malignant melanoma by socioeconomic status in Canada: 1992-2006. J Otolaryngol Head Neck Surg 2015; 44: 53.

34. Siegel RL, Miller KD, Jemal A. Cancer statistics. 2017. CA Cancer J Clin 2017; 67(1): 7-30.

35. Liu F, Bessonova L, Taylor TH, Ziogas A, Meyskens FL Jr, Anton-Culver $\mathrm{H}$. A unique gender difference in early onset melanoma implies that in addition to ultraviolet light exposure other causative factors are important. Pigment Cell Melanoma Res 2013; 26(1): 128-35.

36. Liu-Smith F, Farhat AM, Arce A, et al. Sex differences in the association of cutaneous melanoma incidence rates and geographic ultraviolet light exposure. J Am Acad Dermatol 2017; 76(3): 499-505, e3.

37. Liu-Smith F, Ziogas A. An age-dependent interaction between sex and geographical UV index in melanoma risk. J Am Acad Dermatol 2017, pii: S0190-9622(17)32748-2.

38. Howlader, N, Noone, AM, Krapcho M (eds). SEER cancer statistics review, 1975-2014, National Cancer Institute. Bethesda, MD, http:// seer.cancer.gov/csr/1975_2014/, based on November 2016 SEER data submission, posted to the SEER web site, April 2017.

39. Joosse A, Collette S, Suciu S, et al. Sex is an independent prognostic indicator for survival and relapse/progression-free survival in metastasized stage III to IV melanoma: a pooled analysis of five European organisation for research and treatment of cancer randomized controlled trials. J Clin Oncol 2013; 31(18): 2337-46.

40. Courtenay WH. Constructions of masculinity and their influence on men's well-being: a theory of gender and health. Soc Sci Med 2000; 50(10): 1385-40.

41. Stanton WR, Janda M, Baade PD, Anderson P. Primary prevention of skin cancer: A review of sun protection in Australia and internationally. Health Promotion International 2004; 19(3): 369-78.

42. Hillhouse J, Turrisi R, Stapleton J, Robinson J. A randomized controlled trial of an appearance-focused intervention to prevent skin cancer. Cancer 2008; 113(11): 3059-274.

43. Jackson K, Aiken L. A psychosocial model of sun protection and sunbathing in young women: The impact of health beliefs, attitudes, norms and self-efficacy for sun protection. Health Psychology 2000; 19(5): 469-78.
44. Ghiasvand R, Robsahm TE, Green AC, et al. Association of Phenotypic Characteristics and UV Radiation Exposure With Risk of Melanoma on Different Body Sites. JAMA Dermatol 2019; 155(1): 39-49.

45. Pérez-Gómez B, Aragonés N, Gustavsson P, Lope V, López-Abente G, Pollán M. Do sex and site matter? Different age distribution in melanoma of the trunk among Swedish men and women. Br J Dermatol 2008; 158(4): 766-72.

46. Bevona C, Fewkes J, Liu V, Sober AJ. Prolonged evolution of a lentigo maligna. J Am Acad Dermatol 2004; 51(5): 830-5.

47. Haenssle HA, Mograby N, Ngassa A, et al. Association of patient risk factors and frequency of nevus-associated cutaneous melanomas. JAMA Dermatol 2016; 152(3): 291-8.

48. Whiteman DC, Stickley M, Watt P, Hughes MC, Davis MB, Green AC. Anatomic site, sun exposure, and risk of cutaneous melanoma. J Clin Oncol 2006; 24(19): 3172-7.

49. Whiteman DC, Pavan WJ, Bastian BC. The melanomas: a synthesis of epidemiological, clinical, histopathological, genetic, and biological aspects, supporting distinct subtypes, causal pathways, and cells of origin. Pigment Cell Melanoma Res 2011; 24(5): 879-97.

50. Shain AH, Bastian BC. From melanocytes to melanomas. Nat Rev Cancer 2016; 16(6): 345-58.

51. Gandini S, Sera F, Cattaruzza MS, et al. Meta-analysis of risk factors for cutaneous melanoma: I. Common and atypical naevi. Eur J Cancer 2005; 41: 28-44.

52. Gandini S, Sera F, Cattaruzza MS, et al. Meta-analysis of risk factors for cutaneous melanoma: II. Sun exposure. Eur J Cancer 2005; 41: 45-60.

53. Caini S, Gandini S, Sera F, et al. Meta-analysis of risk factors for cutaneous melanoma according to anatomical site and clino-pathological variant. Eur J Cancer 2009; 45: 3054-63.

54. Olsen CM, Zens MS, Green AC, et al. Biologic markers of sun exposure and melanoma risk in women: pooled case-control analysis. Int J Cancer 2011; 129: 713-23.

55. Demierre MF, Chung C, Miller DR, Geller AC. Early detection of thick melanomas in the United States: beware of the nodular subtype. Arch Dermatol 2005; 141(6): 745-50.

56. Lino-Silva LS, Dominguez-Rodriguez JA, Aguilar-Romero JM, et al. Melanoma in Mexico: clinicopathologic features in a population with predominance of acral lentiginous subtype. Ann Surg Oncol 2016; 23(13): 4189-94.

57. Dal H, Boldemann C, Lindelöf B. Does relative melanoma distribution by body site 1960-2004 reflect changes in intermittent exposure and intentional tanning in the Swedish population? Eur J Dermatol 2007; 17(5): 428-34.

58. Watts CG, Madronio C, Morton RL, et al. Clinical features associated with individuals at higher risk of melanoma: a population-based study. JAMA Dermatol 2017; 153(1): 23-9.

59. Barysch MJ, Levesque MP, Cheng P, et al. Coexpression of SOX10/ CD271 (p75(NTR)) and beta-galactosidase in large to giant congenital melanocytic nevi of pediatric patients. Dermatopathology (Basel) 2014; 1(1): 35-46.

60. Krengel S, Hauschild A, Schafer T. Melanoma risk in congenital melanocytic naevi: a systematic review. Br J Dermatol 2006; 155(1): $1-8$.

61. van der Leest R, Flohil S, Arends L, de Vries E, Nijsten T. Risk of subsequent cutaneous malignancy in patients with prior melanoma: a systematic review and meta-analysis. J Eur Acad Dermatol Venereol 2015; 29(6): 1053-62.

62. Kubica A, Brewer J. Melanoma in immunosuppressed patients. Mayo Clin Proc 2012; 87(10): 991-1003. 